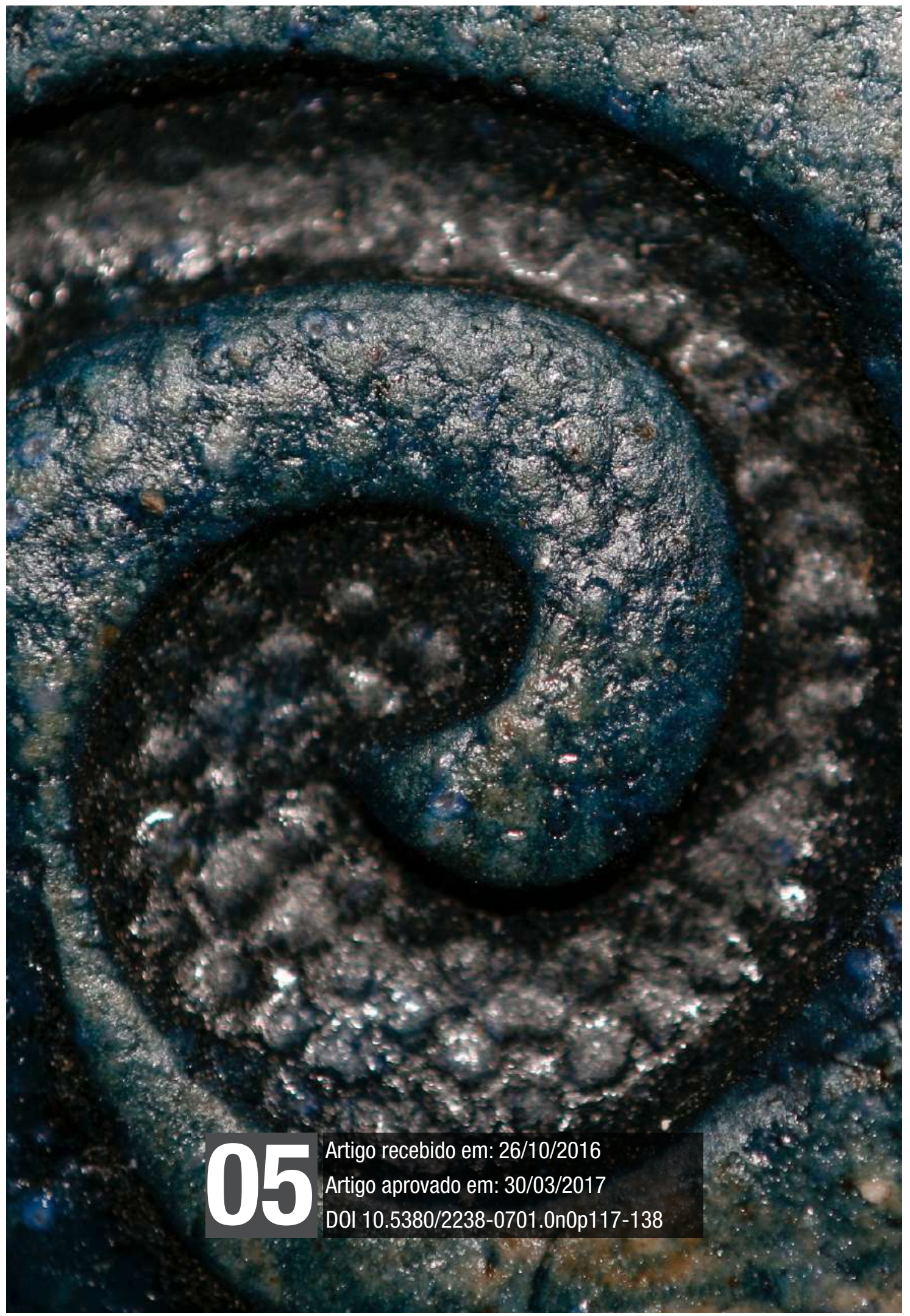


Igualdade de gênero. Discurso midiático. Vozes sociais. 


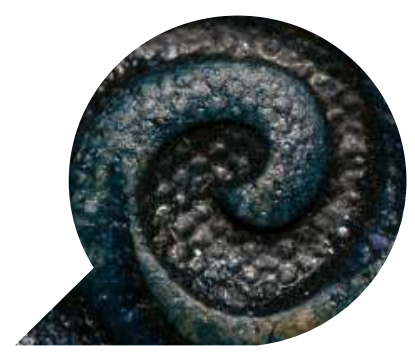

\title{
A polêmica de vozes no discurso da campanha Rasgue o verbo
}

\author{
The debate of voices in the discourse \\ Rasgue o verbo campaign \\ La polémica de las voces en el discurso \\ de la campaña Rasgue o verbo
}

\section{KELLI DA ROSA RIBEIRO ${ }^{1}$}

Resumo: Este artigo pretende analisar a polêmica de vozes sociais instaurada nos enunciados da campanha "Rasgue o verbo" do canal GNT, problematizando, sob um viés dialógico da linguagem, ideias socialmente cristalizadas e propagadas em diferentes discursos. Como embasamento teórico, recorremos à teoria dialógica do discurso, desenvolvida por Bakhtin e seu Círculo, estabelecendo um diálogo com autores que discutem acerca da problemática social do gênero na contemporaneidade e com autores que tratam da mídia e das redes sociais, entendendo que o discurso das mídias promove a popularização de novas formas de se pensar o masculino e o feminino na sociedade. Esperamos fomentar a discussão dialógica de gêneros na mídia, a fim de entendermos

\footnotetext{
${ }^{1}$ Doutora em Linguística pela Pontifícia Universidade Católica do Rio Grande do Sul (PUCRS). Professora Adjunta no Instituto de Letras e Artes, da Universidade Federal do Rio Grande (ILA-FURG). E-mail: klro.rib@gmail.com
} 
questões sociais, culturais e econômicas que envolvem os papéis de homens e mulheres na sociedade atual.

Palavras-chave: Igualdade de gênero; Discurso midiático; Vozes sociais; Análise dialógica.

Abstract: This article aims to analyze the debate on social voices introduced in the utterances of the "Rasgue o verbo" (Shred the word) campaign on the GNT channel, examining the socially established and disseminated ideas in different discourses from a dialogic perspective of language. As a theoretical foundation, we appeal to the dialogic theory of discourse, developed by Bakhtin and his Circle, establishing a dialogue between authors who discuss the social problem of gender today and authors who address the media and social networks. We understand that media discourse promotes the popularization of new forms of thinking regarding masculinity and femininity in society. We intend to promote a dialogic discussion of gender in the media, in order to understand social, cultural and economic issues that involve the roles of men and women in society today.

Keywords: Gender equality; Media discourse; Social voices; Dialogical analysis.

Resumen: El presente artículo pretende analizar las voces sociales polémicas establecidas en las declaraciones de la campaña "Rasgue o verbo" (Tear la palavra) el GNT, cuestionando, en un idioma sesgo dialógica, social las ideas cristalizadas y propagado en diferentes discursos. Como base teórica, nos volvemos a la teoría dialógica del discurso, desarrollado por Bajtín y su círculo y establecer un diálogo con los autores que discuten sobre el género de los problemas sociales en contemporánea y autores que se ocupan de los medios de comunicación y las redes sociales, para entender el habla de medios de comunicación promueven la popularización de las nuevas formas de pensar sobre el macho y la hembra en la sociedad. Esperamos fomentar el diálogo discusión de género en los medios de comunicación, con el fin de entender los problemas sociales, culturales y económicos que afectan a los roles de hombres y mujeres en la sociedad actual.

Palabras clave: La igualdad de género; Discurso de los medios; Voces sociales; El análisis dialógico. 


\section{Primeiras palavras}

A contemporaneidade vê-se marcada, sobretudo nos discursos midiáticos, pelo intenso debate acerca de papéis de homens e mulheres na sociedade. No Brasil, encontramos grande heterogeneidade cultural, e os papéis desempenhados por homens e mulheres evidenciam que há diferentes formas de "ser mulher" e de "ser homem" nas diversas situações sociais. Estudiosos como Joan Scott tratam a categoria gênero em seu aspecto relacional, considerando o caráter intrinsecamente social das diferenças entre feminino e masculino. De acordo com Scott (1990), somente no final do século XX a ideia sobre gênero aparece como uma preocupação de dimensão teórica, não se encontrando em grande parte das teorias sociais, desde o século XVII até o início do século XX.

Entendemos que a linguagem escrita, visual ou falada, nesse cenário, tem papel fundamental na construção da vida em sociedade, como também é fundamental nas relações de gênero. A linguagem constitui as relações valorativas de poder, remetendo dialogicamente a posições atribuídas a homens e a mulheres nos diferentes contextos sociais. Conforme Bakhtin (2003, p. 379), o eu vive em um mundo repleto de palavras do outro e toda a sua vida "é uma orientação nesse mundo". A palavra do outro coloca diante do eu a tarefa de compreendê-la, e mais, a tarefa de atribuir-lhe uma contrapalavra (BAKHTIN, 2003, p. 379).

Assim, podemos afirmar que o ser humano se constrói socialmente pela palavra, pelo discurso dos outros, estabelecendo sua subjetividade a partir das relações com o outro. Por isso, embora seja uma distinção orgânica que defina, numa primeira dimensão, a diferença entre o masculino e o feminino, numa segunda dimensão, essa distinção só se completa num sistema de relações sociais, situada em contextos históricos e culturais, tendo como elemento fundamental a palavra, os discursos que circulam nas diversas esferas da atividade humana.

Buscando entender e aprofundar essas questões, neste artigo, analisamos a polêmica de vozes sociais instaurada nos enunciados da campanha "Rasgue o verbo" do canal GNT, problematizando, sob um viés dialógico da linguagem, ideias socialmente cristalizadas e propagadas em diferentes discursos. Duas perguntas balizam nosso debate: i) que vozes sociais são polemizadas nos enunciados? ii) que imagem de mulher a campanha constrói no discurso? Os enunciados selecionados para a análise são agrupados em dois eixos temáticos: a violência contra 
a mulher e o lugar da mulher na sociedade. A seleção dos enunciados é feita a partir do site do canal GNT na internet. ${ }^{2}$

Nossas discussões procuram mostrar de que forma a ampla circulação de discursos midiáticos fez com que a luta feminista ${ }^{3}$ usufruísse de diferentes ferramentas de combate à violência e ao preconceito contra a mulher. Com o acesso às novas Tecnologias de Informação e Comunicação, observamos que a polêmica contra os discursos da violência e da segregação, carregados de estereotipias, ganha espaços de forma mais intensificada e atinge cada vez mais as camadas populares. Tal movimentação busca não só a conquista de novos direitos, mas também a conquista da autonomia feminina e a relação mais igualitária entre os gêneros.

\section{A noção de polêmica de vozes: contribuições de Bakhtin}

O signo ideológico é o lugar de valores contraditórios, ou seja, o lugar de embate entre múltiplas e diferentes vozes sociais. Bakhtin/Volochinov ([1929] 2010) comparam o signo ideológico a uma "arena", a fim de mostrar o quanto na linguagem se confrontam e entram em choque os valores sociais circundantes, os pontos de vista a respeito de determinado tema e o quanto o sujeito está envolto nesse jogo avaliativo nos diversos contextos de interação.

Nesse cenário, os signos ideológicos verbais e não verbais estão impregnados de já-ditos de outros aos quais respondemos ativamente. Para Bakhtin ([1975] 2010, p. 86), encontramos o objeto do nosso dizer já "desacreditado, contestado, avaliado" e muitas vezes o encontramos envolvido "por uma névoa escura" ou, então, "iluminado pelos discursos de outrem que já falaram sobre ele”. Do ponto de vista bakhtiniano, o objeto do nosso dizer está sempre no emaranhado de vozes sociais.

Tais vozes são históricas, ideológicas e revelam as diversas posições que rodeiam um discurso. Em todo o discurso percebe-se um meio flexível de dizeres de outrem em pelo menos duas dimensões: entre o dis-

\footnotetext{
${ }^{2}$ Disponível em: http://gnt.globo.com/especiais/eles-por-elas/infograficos/rasgue-o-verbo.htm Acesso em: 15 de jul. 2016.

${ }^{3} \mathrm{O}$ feminismo é uma filosofia que reconhece que homens e mulheres possuem experiências diferentes e reivindica que pessoas diferentes sejam tratadas não como iguais, mas como equivalentes. 0 movimento feminista denuncia que a experiência masculina tem sido privilegiada ao longo da história da sociedade, enquanto a feminina, negligenciada e desvalorizada. Esse pensamento demonstra, ainda, que o poder foi - e ainda é - predominantemente masculino, e seu objetivo original foi a dominação das mulheres, especialmente de seus corpos. Por isso, o discurso feminista propaga direitos equânimes, bem como uma vivência humana que oportunize o empoderamento feminino e liberte as mulheres de padrões opressores patriarcais, baseados em normas de gênero (NARVAZ; KOLLER, 2006).
} 
curso e o objeto do dizer e entre o locutor e o objeto. O meio flexível existente entre esses elementos é formado por uma "massa de discursos" de outrem que orientam uma apreciação sobre o objeto. É nesse processo de mútua interação entre locutor, objeto e discursos de outrem que o discurso se individualiza e se elabora estilisticamente (BAKHTIN [1975] 2010, p. 86).

Nesse sentido, Bakhtin/Volochinov ([1929] 2010, p. 140) observam que toda a enunciação se constrói tendo como base uma "orientação apreciativa”. A orientação apreciativa faz parte do processo de compreensão da enunciação do outro. Bakhtin/Volochinov ([1929] 2010, p. 137) afirmam que o ato de compreender "a enunciação de outrem significa orientar-se em relação a ela”. E nessa orientação para um novo contexto surge um novo sentido, sempre avaliado e atualizado pela entonação do sujeito. Tomando a palavra nessa direção, Bakhtin/Volochinov ([1929] 2010, p. 137) salientam que compreender é opor “à palavra do locutor uma contrapalavra”, ou seja, a nova palavra (a contrapalavra) traz consigo alguns aspectos: o aspecto da enunciação proferida (a palavra do locutor), o aspecto da significação do aparato técnico da palavra e, por fim, o aspecto do novo sentido, da nova apreciação, resultante do processo de compreensão.

A compreensão sempre ativa e responsiva em direção ao discurso do outro move dialogicamente os processos de apreensão e transmissão do discurso alheio, arena na qual se dá a polêmica de vozes. Para Bakhtin ([1963] 2010b, p. 228), "as relações de reciprocidade com a palavra do outro no contexto vivo e concreto não têm caráter estático, mas dinâmico", de modo que a "inter-relação das vozes no discurso pode variar acentuadamente, o discurso orientado para um único fim pode converter-se num discurso orientado para diversos fins" e vice-versa (BAKHTIN [1963] 2010b, p. 228).

Bakhtin ([1963] 2010b) ainda discute a respeito de diversos gêneros discursivos que apresentam esse grau vário de orientação em relação à voz do outro e em relação ao contexto. De acordo com o autor, o discurso bivocal é essencialmente um discurso voltado para o discurso do outro e pode ter três tipos ou tendências de orientações. A primeira orientação é o "discurso bivocal de orientação única", em que há um efeito de fusão de vozes, pois o discurso que se apropria da voz alheia tem a mesma orientação semântica (valorativa) da voz transmitida. $\mathrm{O}$ diálogo e as fronteiras com o discurso alheio tendem a ficar mais diluídas, criando o efeito de uma só voz, de uma só orientação axiológica. 
A segunda orientação Bakhtin ([1963] 2010b, p. 228) chama de "discurso bivocal de orientação vária", em que o diálogo entre as vozes pode aparecer mais perceptível no discurso. Compreendemos que é "vária", pois a orientação do discurso que transmite está em direção oposta semanticamente ao discurso alheio, como é na paródia, por exemplo. Na segunda orientação, a dialogicidade interna aparece reverberada no discurso, permitindo que se estabeleça ainda o diálogo com outras vozes sociais sobre o mesmo objeto do dizer (BAKHTIN [1963] 2010b, p. 228).

As transmissões de orientação "vária” podem ser caracterizadas também como variações da polêmica aberta no discurso. Conforme Bakhtin ([1963] 2010b, p. 224), “a polêmica aberta está simplesmente orientada para o discurso refutável do outro". Diferentes tons podem marcar a oposição das vozes no discurso, ou seja, a palavra alheia pode ser introduzida com acentos e expressões de indignação, zombaria, ironia, dúvida e os modos de transmissão dessa polêmica podem variar em estilo.

Por fim, a terceira orientação Bakhtin ([1963] 2010b, p. 229) denomina de "tipo ativo (discurso refletido do outro)". A orientação é em direção ao diálogo tenso com o outro que aparentemente não está presente no discurso, ou seja, é como se a voz do outro estivesse ali, mas ela aparece refrangida na polêmica instaurada, podendo aparecer ou não as fronteiras. A voz alheia aparece escamoteada, velada, refletida no discurso que transmite.

A bivocalidade de tipo ativo aparece em diferentes tons de uma polêmica mais velada no discurso. Segundo Bakhtin ([1963] 2010b), na polêmica velada as vozes se chocam de maneira conflituosa, mas diferentemente da polêmica aberta, o choque entre as vozes acontece de forma indireta, escamoteada no próprio discurso objetal do autor. A polêmica velada fica impressa no discurso bivocal também por meio dos elementos não verbais que compõem o contexto da interação, tais como imagens, gestos corporais, expressões faciais, entonação da voz etc. As polêmicas, em síntese, estão no plano axiológico do conhecimento compartilhado entre os sujeitos do discurso e só são perceptíveis na dimensão dialógica da interação.

Na mídia, conforme discutimos na próxima seção, há um largo espaço para esse embate, sobretudo no que tange ao encontro de vozes que polemizam questões que envolvem o feminino na sociedade contemporânea. 


\section{Discussões de gênero na mídia: contextualizando a campanha Rasgue o verbo}

O gênero é uma maneira de existir do corpo e as relações corporais acontecem sempre situadas num campo de possibilidades culturais recebidas e reinterpretadas a todo o instante. Concordamos com estudiosos como Saffioti (1992), quando destacam que o corpo de uma mulher é essencial para definir sua situação no mundo, mas é insuficiente para defini-la como mulher. A definição da sua feminilidade só se processa através da atividade desta mulher nos diversos setores da sociedade. Isto significa dizer que o gênero se constrói e se expressa através das diferentes relações sociais (SAFFIOTI, 1992, p. 189).

As relações de gênero são dialógicas e dialéticas, refletindo contradições e concepções de gênero internalizadas por diferentes atores sociais. Quando se trata da categoria "relações de gênero", devese entender que mulheres e homens vivenciam relações e experiências distintas, visto que na sociedade contemporânea não existe igualdade de gênero desde as situações mais simples até as mais elaboradas e complexas. Ainda há grande segregação em relação às mulheres que, aos poucos, ocupam os espaços tradicionalmente destinados aos homens.

Embora a mulher tenha obtido avanços em suas reivindicações, e tenha inclusive ingressado massivamente no mercado de trabalho, a discriminação sexual, por exemplo, é um fato alarmante. Todos os dias a mídia noticia casos de violência doméstica contra a mulher, casos de estupro e pedofilia em que a vítima, muitas vezes, ainda é colocada como culpada. O discurso feminista, nesse contexto, tenta atribuir sua contrapalavra, nesses casos, alegando que em situações de violência a sociedade passe a criminalizar o agressor, e não a vítima, tenha ela qualquer comportamento.

Em maio de 2016, um caso de estupro coletivo ${ }^{4}$, numa favela do Rio de Janeiro, efervesceu o debate em torno da violência contra a mulher e da frequente (e histórica) culpabilização da vítima. O caso envolveu uma jovem de 16 anos que foi violentada por 33 homens armados com pistolas e fuzis. $\mathrm{O}$ vídeo, postado por um dos estupradores, mostrando

\footnotetext{
4 Disponível em: http://g1.globo.com/rio-de-janeiro/noticia/2016/05/vitima-de-estupro-coletivo-no-rioconta-que-acordou-dopada-e-nua.html Acesso em: 09 de jul. 2016. http://noticias.band.uol.com.br/brasilurgente/videos/15875174/adolescente-e-vitima-de-estupro-coletivo-no-rio-de-janeiro.html Acesso em: 23 de fev. 2017. http://oglobo.globo.com/rio/quando-acordei-tinha-33-caras-em-cima-de-mim-diz-meninaque-sofreu-estupro-coletivo-19380492 Acesso em: 24 de fev. 2017.
} 
o ato da agressão, circulou em redes sociais, fazendo com que o episódio fosse discutido na esfera jurídica, pois havia ainda a dúvida acerca do estupro. Essa discussão tomou conta das diferentes mídias e um turbilhão de opiniões e vozes surgiram nas redes, principalmente no Facebook, rede social de abrangência mais popular.

$\mathrm{O}$ movimento feminista tem se valido das redes sociais para problematizar essas questões. Através da construção da memória social e da identidade, a linguagem utilizada pelas redes permite que as informações, opiniões, estereótipos e suas quebras tenham uma abrangência globalizada. Conforme Charaudeau (2010, p. 19), a mídia se encontra na "contingência de dirigir-se a um grande número de pessoas, ao maior número, a um número planetário, se possível”. Para despertar o interesse e tocar a afetividade do destinatário, a quem se dirige a informação, a mídia distribui os posicionamentos de forma que atinja o maior número de pessoas, simplificando conceitos, criando clichês, estereótipos.

A esfera midiática e principalmente as redes sociais selecionam o que será difundido no espaço virtual, construindo-se uma imagem fragmentada do espaço público, uma visão adequada aos objetivos das mídias. Tal fragmentação é pertinentemente adequada aos objetivos da mídia: visando atingir o maior público possível, é vantagem que apareçam diversificados reflexos da realidade social de maneira que atinja as diversas opiniões, valores, crenças etc.

Segundo Amossy (1991), os estereótipos são imagens preconcebidas, sob a influência do meio social, carregando consigo uma ideia preconcebida, pré-fabricada, prejulgada, de alguém, de algo, de um fato etc. Nessa direção, podemos entender que o estereótipo não é um conceito teórico absoluto e eterno, mas uma noção resultante da época moderna, das relações sociais. O processo de estereotipia não existe em si; ele é fomentado na própria sociedade e nas relações humanas, pelos diversos discursos da coletividade.

A autora mostra o exemplo de estereótipos que envolvem as mulheres, criando uma imagem de certa forma cristalizada de que "as mulheres são submissas, dependentes, doces, passivas, desprovidas de ambição, sensíveis aos sentimentos do outro, mais emotivas". Já sobre os homens, criam-se estereótipos diferentes, ou seja, os discursos produzidos pela coletividade colocam os homens como "brutos, rudes, inconscientes dos sentimentos dos outros, agressivos, dirigentes, confiantes neles mesmos, aventureiros, lógicos, competitivos, decididos, dominadores" (AMOSSY, 1991, p. 171). 
Compreendemos, dessa maneira, que, no processo de estereotipia, está subjacente um processo de (pré)julgamento de valor que em muitos casos pode ser nocivo à sociedade, como por exemplo, os inúmeros casos de racismo e discriminação. De forma crítica, Amossy (1991, p. 15) alerta que "só um movimento perpétuo de transgressão e de desconstrução pode evitar que formem também novas imagens coletivas".

Nesse contexto, o Facebook torna-se um espaço bastante dialético de circulação de valores de gênero, sendo palco de embates entre vozes estereotipadas e vozes de quebra e de polêmica ao estereótipo. Empresas de diferentes ramos mercadológicos se valem do espaço e do embate, a fim de promover o consumo de marcas, produtos e serviços. Isso acontece, segundo Pompeu (2014), porque o Facebook, como outras redes sociais, são complexos sistemas comunicação, no qual diversas marcas ocupam o universo digital como ferramenta de divulgação de produtos e conceitos. Essa divulgação rearranja os vínculos entre pessoas e instituições, fazendo com que a relação publicitária que subjaz o processo seja também uma relação emocional, cultural e social.

Inserindo a campanha Rasgue o Verbo, do canal GNT, nesse contexto, embora ela não se limite a circular nessa rede, podemos visualizar concretamente essas questões. A campanha procura se aliar a vozes feministas de luta contra a desigualdade de gêneros e o faz baseandose em duas dimensões: a primeira dimensão é a simbólica, na qual a campanha propagandista promove o debate de uma situação social contemporânea de luta contra discursos preconceituosos e machistas que circulam em diferentes esferas da comunicação, afetando diretamente a vida de homens e mulheres ao longo da história. A segunda dimensão é a mercadológica, na qual a marca/empresa GNT (vinculada à Rede Globo) faz circular seu universo de signos, promovendo o consumo de sua programação e conquistando espaço na concorrência midiática.

O site da campanha afirma que "Rasgue o Verbo" é uma ferramenta do GNT que abre espaço para ajudar a desconstruir frases do cotidiano repletas de preconceitos. Segundo o site, “'Rasgue o Verbo' vai mostrar que não há preconceito inocente" ${ }^{\text {. }}$. A campanha é vinculada à $O N U M u$ lheres e ao movimento "HeForShe", criado em Nova York, no dia 20 de setembro de 2014. Em julho de 2010, a Assembleia Geral da ONU (Organização das ções Unidas) criou a ONU Mulheres, Entidade das Nações

\footnotetext{
${ }^{5}$ Disponível em: http://gnt.globo.com/especiais/eles-por-elas/infograficos/rasgue-o-verbo.htm Acesso em: 09 de jul. 2016.
} 
Unidas para a igualdade de gênero e empoderamento das mulheres. $\mathrm{Na}$ Figura 1, podemos visualizar o layout da campanha no site que tem links diretos com as principais redes sociais:

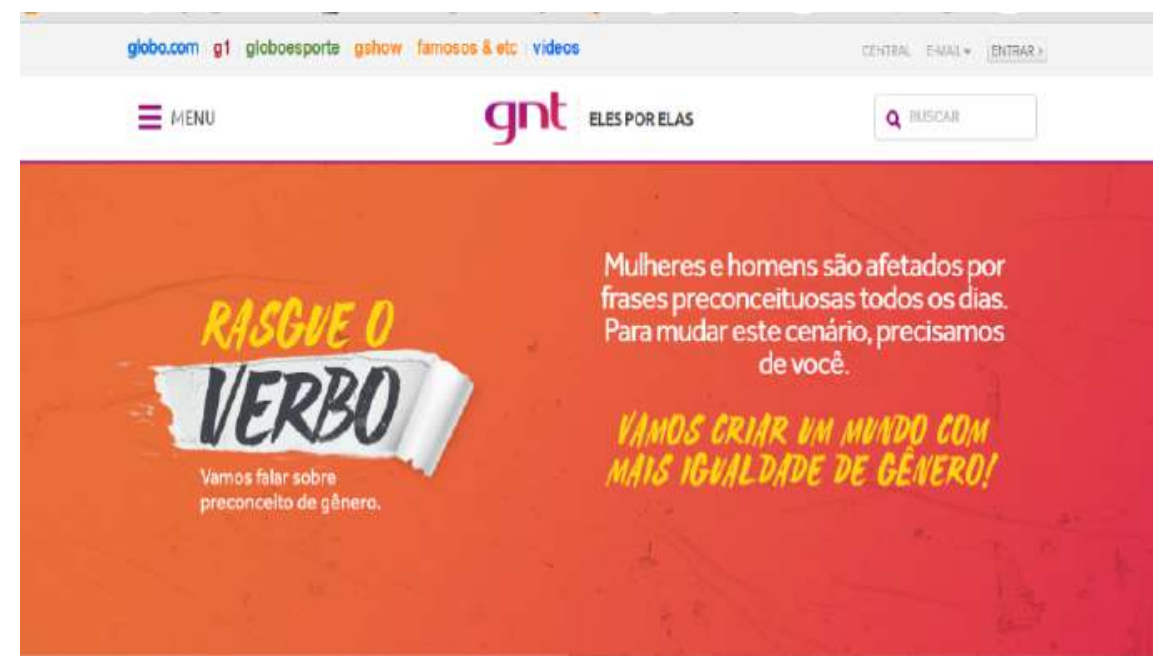

Figura 1: Imagem de abertura da campanha no site da campanha.

A tentativa da campanha, numa dimensão simbólica, é instigar a discussão e a reavaliação de conceitos cristalizados acerca de identidades femininas e masculinas. Numa ação discursiva de descontruir frases consideradas preconceituosas, a campanha Rasgue o Verbo propõe mudar o discurso, romper ideias (pre)concebidas, descartar a violência de gênero. É possível afirmar que publicidades que abordem a temática dessa maneira contribuem para a reformulação e quebra de estereotipias a longo prazo, numa cadeia de tensões entre vozes que propagam ideias já cristalizadas e vozes que propõem sentidos atualizados.

Na grade de programação do GNT, na TV a cabo, pudemos observar a campanha na versão televisiva em que homens e mulheres rasgam literalmente as frases escritas em cartazes em preto e branco, fazendo aparecer novas/outras frases de empoderamento, nas quais a igualdade de gênero ganha tom positivo no cenário. À medida que as pessoas rasgam as frases preconceituosas, surge, aos poucos, no centro do painel a seguinte frase com letras em caixa alta e em tons de vermelho: "Colocar-se no lugar do outro faz do mundo um lugar de todos”. A Figura 2 aparece no site e na campanha televisiva: 


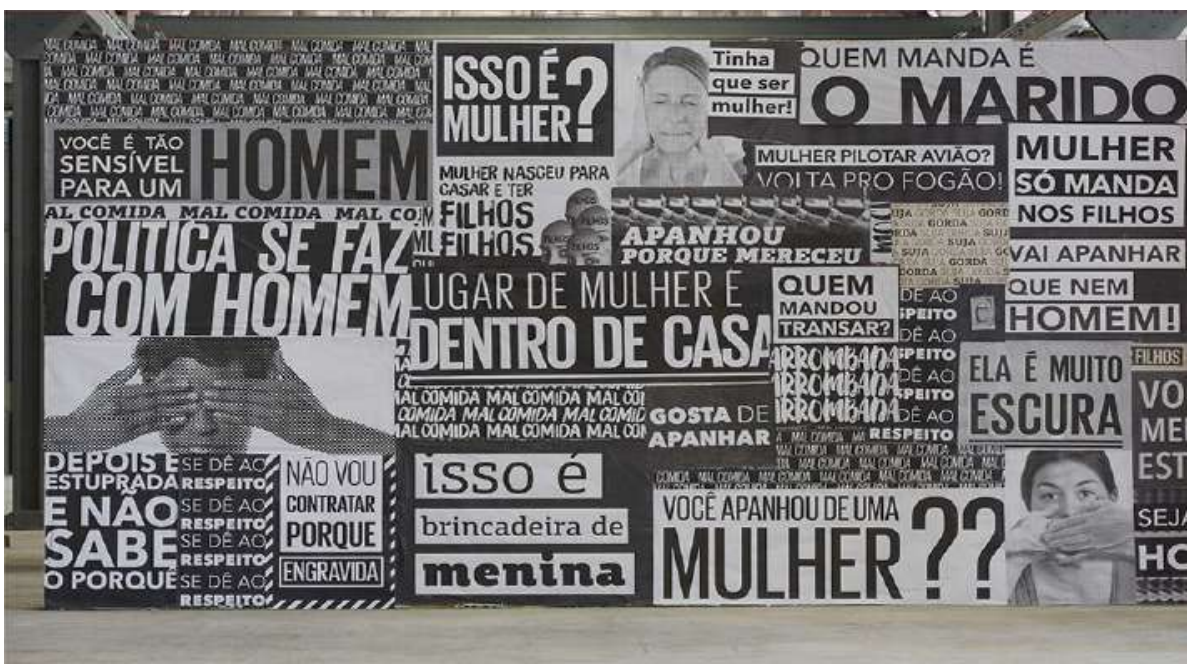

Figura 2: Frases para serem rasgadas na campanha retiradas do site do GNT.

O site orienta os internautas a "entrarem no jogo" de rasgar o verbo e romper com os estereótipos de gênero, fazendo um tutorial que ensina a compartilhar as frases nas redes sociais. Observando a campanha em seu funcionamento midiático, nos diferentes dispositivos, é possível perceber a instauração de uma rede de compartilhamentos que engaja o público na dimensão simbólica de discussão de questões sociais de gênero e na dimensão mercadológica de difusão da marca GNT. Abaixo, os passos para entrar na rede de quebra das frases:

\section{VEJA COMOFUNCIONA}
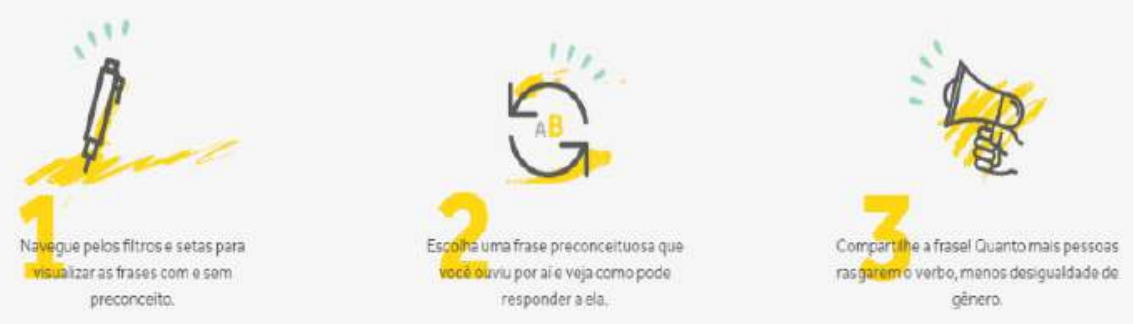

Figura 3: Tutorial da campanha, retirado do site da campanha. 
As frases são agrupadas em quatro categorias que abrangem a vida cotidiana de homens, mulheres e crianças: Trabalho, Violência, Comportamento e Infância. Num primeiro cartaz, aparece uma frase ligada a vozes preconceituosas que circulam em diferentes esferas e no segundo cartaz, já com a marca sígnica do rasgo, a frase é reelaborada de modo a ligar-se a discursos feministas que lutam pela igualdade de gênero. $\mathrm{Na}$ Figura 4, é possível observar uma das frases:

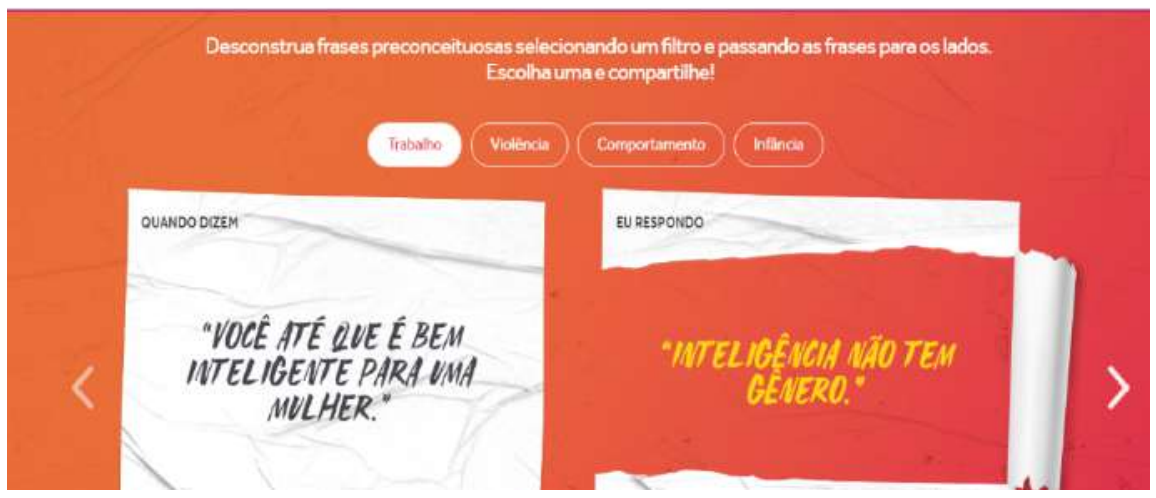

Figura 4: Imagem da frase antes e depois de ser rasgada, retirada do site do GNT.

A análise proposta, neste artigo, pretende problematizar os enunciados da campanha, aprofundando questões de gênero e estereotipia no âmbito discursivo midiático. Para tanto, analisamos a polêmica de vozes sociais nos enunciados da campanha, observando sob um viés dialógico da linguagem, ideias socialmente cristalizadas e propagadas em diferentes discursos. Duas perguntas balizam nosso debate: i) que vozes sociais são polemizadas na campanha? ii) que imagem de mulher a campanha constrói no discurso?

Selecionamos quatro enunciados polemizados que representam eixos analíticos por nós enfatizados: a violência contra a mulher e $o$ lugar da mulher na sociedade. Procuramos entender o que afinal significa "Rasgar o Verbo", na dimensão social proposta pelo GNT.

\section{A polêmica em análise: o que é rasgar o verbo?}

As frases polemizadas na campanha Rasgue o verbo questionam imagens cristalizadas (estereotipadas) sobre homens e mulheres que circulam em diferentes discursos na sociedade. Tais (pre)conceitos criam 
uma problemática que envolve diretamente as mulheres na dimensão da sua vida doméstica e na dimensão da sua vida na coletividade: no mercado de trabalho, na política, em locais públicos etc. $\mathrm{O}$ primeiro eixo temático destacado, nessa discussão, problematiza vozes sociais que propagam a violência contra a mulher e os discursos que culpabilizam a vítima de violência.

\section{EIXO: A violência contra a mulher}

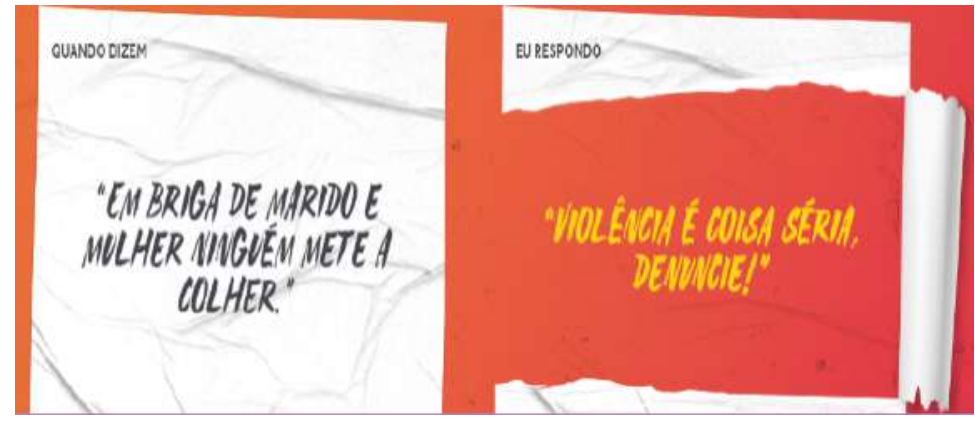

Figura 5: Frase rasgada 1

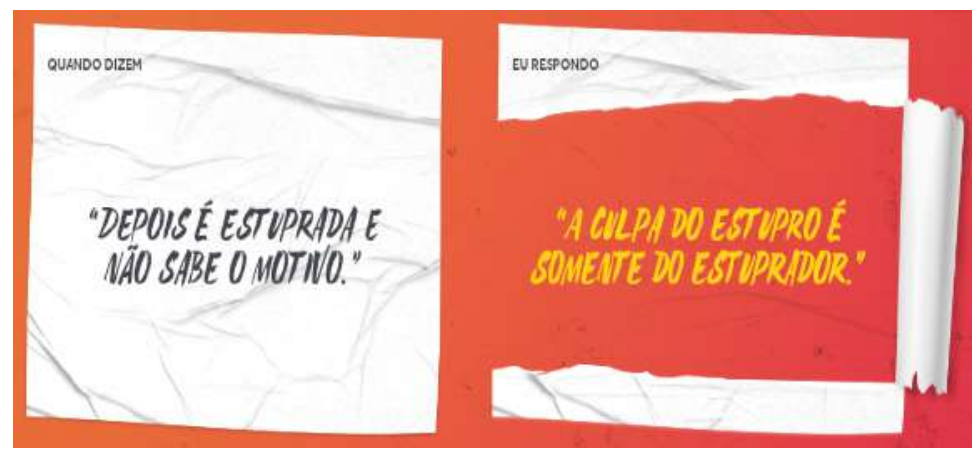

Figura 6: Frase rasgada 2

A polêmica de vozes nos enunciados em destaque é marcada pela oposição de valores concernentes às avaliações sociais sobre violência contra a mulher. Na Figura 5, percebemos, veladamente, o surgimento de vozes sociais que naturalizam a violência doméstica e que colocam a mulher na passividade da agressão. Tal naturalização é combatida pela ressignificação do ditado popular "Em briga de marido e mulher ninguém mete a colher" para o imperativo expresso no enunciado "vio- 
lência é coisa séria, denuncie!". O enunciado rasgado, polemizado, abre espaço para a denúncia, para a criminalização da violência doméstica.

Os valores em oposição se constroem a partir de sentidos que transitam da ideia de naturalidade da violência para a ideia de criminalização e denúncia do agressor. O ditado popular polemizado propaga a não intromissão de testemunhas na briga (não meter a colher), gerando uma grande rede histórica de omissão diante da violência doméstica. Além disso, o signo "briga" atenua situações periclitantes de violência, que vão desde agressões verbais e psicológicas, humilhações até espancamentos, estupros, assassinatos etc.

Se a situação de violência é atenuada de um lado, pelo signo "briga”, por outro, a contrapalavra da campanha ao ditado parece também amenizar a situação. Os signos "coisa séria" tonalizam a ação criminosa com vagueza, com generalização, visto que a palavra "denuncie!” pode pressupor a ideia de crime, de infração, no contexto em que aparece no enunciado. Esse tom de vagueza perpassa a maioria dos enunciados da campanha, talvez pelo caráter mercadológico que envolve esse discurso. O projeto do GNT, nesse discurso, é promover um debate acerca das questões de gêneros, mas a acusação direta com signos como "crime", por exemplo, poderia atingir de forma negativa determinado nicho de seus consumidores.

$\mathrm{Na}$ Figura 6, a polêmica parece estar mais evidente, mais aberta contra a estereotipia em vozes que propagam que a culpa do estupro é da vítima/mulher. Tais vozes culpabilizam a vítima, questionando-a acerca de sua roupa, companhias, comportamentos etc. $\mathrm{O}$ enunciado "depois é estuprada e não sabe o motivo" é uma forma sutil e cruel de colocar a culpa, pois fecha o espaço para a culpabilização do estuprador. Esse comportamento social tem base na ideia de posse masculina sobre o corpo feminino. O homem é culturalmente colocado como o dominador, o mais forte na relação, o que exerce poder em vários sentidos. Essas ideias tão enraizadas em diferentes esferas da sociedade construíram o ambiente hostil para a mulher, a quem é atribuída a responsabilidade de não ser estuprada.

O enunciado rasgado, que propõe a polêmica aberta à culpabilização da vítima de estupro, faz emergir a oposição valorativa da culpa: vítima versus estuprador. O uso da palavra "somente" no enunciado "a culpa do estupro é somente do estuprador" restringe os sentidos de responsabilização para o agressor que nesse enunciado é devidamente nomeado com o signo "estuprador". A polêmica instaurada, a longo pra- 
zo, poderá (res)significar os comportamentos que são constantemente reavaliados via discurso.

A partir das vozes em jogo e do embate de valores que tenta descontruir, romper com a ideia da naturalização da violência e da culpabilização da vítima de estupro, percebemos que se engendram no discurso diferentes imagens de homens e mulheres na sociedade, revelando outros sentidos às relações de gêneros. Cria-se a imagem de mulher que reage à violência, denunciando e exigindo punição ao agressor dentro da esfera doméstica e fora dela. Aliada a essa imagem, fomenta-se a conscientização social da violência contra a mulher, criando uma imagem masculina também de quem denuncia e que não é conivente com agressões.

Nessa perspectiva, percebemos o surgimento de uma mulher empoderada do seu próprio corpo, que se veste como lhe convém e que não merece ser estuprada por isso. Essas imagens fazem com que se rompa (rasgue) com a estereotipia que propaga e alimenta a violência, mesmo que a polêmica tenha sido, de alguma forma, atenuada para atingir consumidores midiáticos.

2० EIXO: O lugar da mulher na sociedade

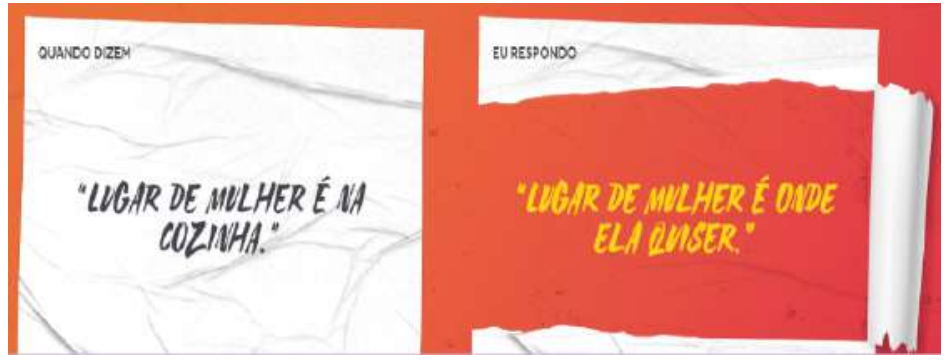

Figura 7: Frase rasgada 3

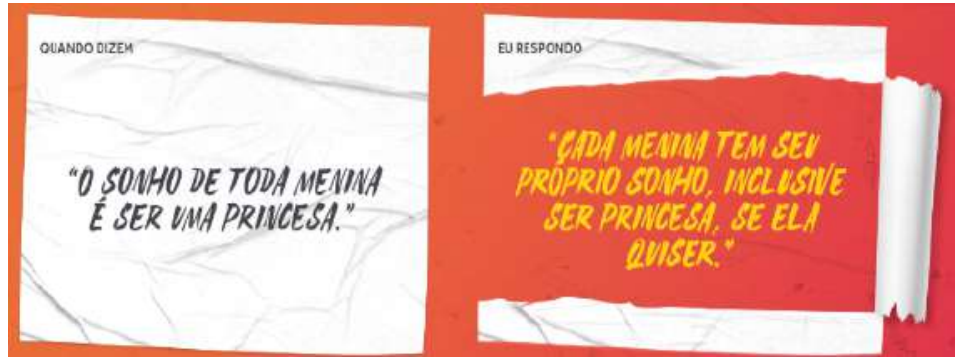

Figura 8: Frase rasgada 4 
No eixo anterior, discutimos acerca de uma violência mais explícita arquitetada pelas vozes sociais em jogo. No presente eixo, tratamos do lugar da mulher na sociedade e como sua imagem foi associada à fragilidade e à passividade ao longo da história. Essa imagem tem colocado a mulher a mercê dos tipos de violência das quais tratamos anteriormente. Os enunciados, em análise, no segundo eixo, polemizam vozes sobre a mulher na fase adulta e da mulher na infância, quando ainda menina é direcionada a ocupar um lugar de subordinação.

$\mathrm{Na}$ Figura 7, percebemos a polêmica por meio de vozes sociais que segregam à mulher as atividades domésticas. O enunciado "lugar de mulher é na cozinha", ditado popular conhecido, é trazido à polêmica para mostrar o fechamento e a restrição das mulheres em diversas atividades laborais fora do lar. Muitos empregos são destinados majoritariamente aos homens, seja pelo argumento da força física, seja pelo argumento da supremacia de inteligência masculina. A essas vozes se aliam ainda diversos dizeres que vinculam a mulher à maternidade como dom inato, instintivo, impondo-lhe a restrição ao lar e à família. O signo "cozinha", metonimicamente, representa a segregação a um tipo de atividade, geralmente não remunerada, deixando a mulher sob domínio masculino, num ciclo de dependência e de falta de voz.

A polêmica proposta pela campanha no enunciado rasgado, a qual atribui novos sentidos ao ditado popular que delega a cozinha como o lugar que deve ser ocupado pela mulher, deixa entrever a problematização da campanha no que tange à escolha de lugares a ocupar. No entanto, quando o enunciado que rompe ressalta "lugar de mulher é onde ela quiser", percebemos o tangenciamento da polêmica, através do tom generalizante da proposta. $\mathrm{O}$ enunciado faz surgir a ideia de que à mulher cabe a escolha de ocupar o lugar que pretender na sociedade, mesmo a cozinha que tradicionalmente lhe cabe.

É possível problematizar essa polêmica destacando três pontos. O primeiro se refere às oportunidades: a mulher só ocupa lugares sociais com igualdade de funções e respeito, quando tem oportunidade, ou seja, é preciso mais do que sua própria vontade de ocupar lugares. $\mathrm{O}$ segundo ponto se relaciona com o primeiro e se refere às políticas públicas para que a mulher tenha esse lugar fora da cozinha garantido. O terceiro ponto é a mudança de sentidos em relação à cozinha que deve ser o lugar de todos em uma casa, sendo superada a vinculação das imagens da mulher e da cozinha. 
Se a imagem da mulher vinculada à cozinha ainda é uma problemática contemporânea, a associação da imagem da princesa à menina também é uma questão social e cultural que precisa ser discutida. $\mathrm{Na}$ figura 8 , a polêmica é direcionada às vozes que determinam comportamentos, sonhos e ideais de vida das mulheres em torno dos sentidos que envolvem a princesa, o conto de fadas, o encantamento. O signo "princesa" evoca sentidos centrados na beleza feminina, nos comportamentos considerados fúteis, nos padrões europeus de beleza. À mulher cabe sonhar em alcançar esses padrões e quando ela não possui esse sonho é considerada masculinizada, desleixada etc.

O enunciado rasgado que rompe com essas vozes também atenua a polêmica, deixando a possibilidade do sonho de se enquadrar no perfil de princesa aliado à possibilidade de não se enquadrar. Por um lado, é positiva a abertura de outras possibilidades a partir do enunciado "cada menina tem seu próprio sonho", singularizando os ideais de vida que podem ser múltiplos. Por outro lado, acreditamos que a polêmica poderia problematizar ainda mais esse padrão de princesa, deixando o próprio padrão mais maleável. Deixar o padrão princesa como possibilidade é uma estratégia mercadológica do GNT que tem diversos programas em sua grade de programação destinados à beleza, à moda e ao comportamento que agregam diferentes padrões, inclusive o padrão princesa. A polêmica, portanto, não pode atingir negativamente a instância consumidora, isto é, seu público.

A partir das polêmicas instauradas e eventualmente atenuadas pela campanha, apreendemos a imagem discursiva de uma mulher que busca seu espaço na sociedade para além da cozinha e com ideais de vida que ultrapassam a ideia de ser bonita, sensual, recatada, sentidos evocados do signo "princesa". Observamos a imagem feminina com poder de escolha, embora saibamos que poder de escolha completamente autônomo depende de uma educação social mais ampla que atinja homens e mulheres em diferentes esferas da atividade.

Assim, entendemos que rasgar o verbo significa romper com a imagem cristalizada de que mulheres são submissas, dependentes, doces, passivas, desprovidas de ambição, sensíveis aos sentimentos do outro, mais emotivas. É romper também com a ideia de que os homens são brutos, rudes, inconscientes dos sentimentos dos outros, agressivos, confiantes neles mesmos, aventureiros, lógicos, competitivos, dominadores. 


\section{Considerações finais}

A discussão acerca de estereótipos de homens e mulheres (em suas diversas materializações no campo midiático) contribui para verificar a presença de violências de variadas naturezas, tais como físicas, sexuais, psicológica etc. A tentativa da campanha do GNT pode ser vista como o início dessa discussão nas mídias, atingindo, em longo prazo, outras esferas da atividade humana. A ação de rasgar o verbo, romper com as vozes, por meio da polêmica no âmbito do discurso, é o primeiro passo para construir uma nova imagem para a relação de gêneros, qual seja, uma imagem de igualdade de direitos e deveres. A tendência é de que outros sentidos sejam construídos para estes papéis, através do intenso embate entre vozes sobre o tema.

A publicidade é um discurso que, no seu engendramento sígnico e imagético, contém grande força no rompimento de estereótipos, uma vez que é também um grande responsável pela cristalização de certas imagens sociais. Por isso, anúncios do tipo da campanha do GNT, em parceria com outras movimentações culturais, possuem potencial para avolumar o debate acerca das relações de gêneros, promovendo um caminhar em direção à igualdade entre homens e mulheres nos diversos setores da sociedade.

Conforme ressaltamos na análise, acreditamos que essa igualdade é também ensejada através de políticas públicas que favoreçam a colocação da mulher de forma igualitária e humana nas relações de trabalho, punindo-se abusos, discriminações e violências de todos os tipos. Além disso, concordamos com Amossy (1991), quando a autora ressalta que mudanças nos estereótipos propagados pela mídia são fundamentais para a superação de ideias socialmente cristalizadas que levam à segregação. É preciso, então, problematizar o discurso cristalizado (sutil ou não) que segrega, a fim de superar a própria segregação de gênero nas diferentes práticas sociais.

Essas mudanças, no campo midiático, podem ocorrer tanto nas sutilezas das personagens em novelas, filmes e propagandas, quanto na discriminação e na ridicularização da mulher em programas humorísticos. Os agentes responsáveis pelo engendramento das informações na mídia precisam ser conscientes da força motriz desta esfera na propagação e na desconstrução de imagens sociais cristalizadas. 


\section{REFERÊNCIAS}

AMOSSY, Ruth. Les idées reçues. Sémiologie du stétéotype. Poitiers: Éditions Nathan, 1991.

BAKHTIN, Mikhail. (VOLOCHINOV, V. N.) Marxismo e Filosofia da linguagem: Problemas fundamentais do método sociológico na ciência da linguagem. (1929). Trad. Michel Lahud e Yara Frateschi Vieira. 12. ed.São Paulo: Hucitec, 2010.

BAKHTIN, Mikhail. Estética da criação verbal [1979]. Trad. Paulo Bezerra. 4. ed. São Paulo: Martins Fontes, 2003.

. Questões de Literatura e de Estética: a teoria do romance [1975]. Trad. Aurora F. Bernardini et. al. 4. ed. São Paulo: Editora da UNESP, Hucitec, 2010.

. Problemas da poética de Dostoiévski. [1963]. Trad. Paulo Bezerra. Rio de Janeiro: Forense, 2010b.

CHARAUDEAU, P. Discurso das Mídias. Trad. Angela S. M. Correa. São Paulo: contexto, 2010.

NARVAZ, M. G.; KOLLER, S. H. Metodologias feministas e estudos de gênero: articulando pesquisa, clínica e política. In: Psicologia em Estudo. Maringá, v. 11, n. 3, p. 647-654, set./dez. 2006.

POMPEU, Bruno. Os significados de consumir em tempos de redes sociais: comprar, vincular, curtir? In: Ciberpublicidade: discurso, experiência e consumo na cultura transmidiática. ATEM, Guilherme; OLIVEIRA, Thaiane; AZEVEDO, Sandro (Org.). Rio de Janeiro: E-papers, 2014.

SAFFIOTI, Heleieth I. B. Rearticulando Gênero e Classe Social. In: Uma questão de Gênero. BRUSCHINI, Cristina; COSTA, Albertina de Oliveira (Org.). Rio de janeiro: Rosa dos Tempos; São Paulo: Fundação Carlos Chagas, 1992.

SCOTT, Joan. Gênero: uma categoria útil de análise histórica. In: Educação e Realidade. Porto Alegre, v.16, n.2, p., 5-22, jul/dez., 1990. 
AÇÃO MIDIÁTICA, n.13. Jan./Jun. 2017. Curitiba. PPGCOM-UFPR. ISSN 2238-0701

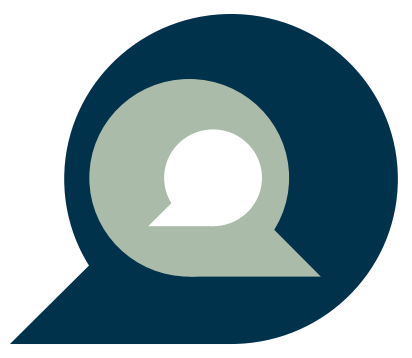

